\title{
Cytokeratin expression in human arteries pertinent to intimal thickening formation in the ductus arteriosus
}

\author{
Accepted in revised form: 13 March 1997
}

\begin{abstract}
Expression of epithelial cytokeratins type 8, 18 and 19 can be used to study smooth muscle cell differentiation during development. We studied the differentiation of smooth muscle cells in the ductus arteriosus before and during intimal thickening and compared the changes occurring in this vessel with the adjoining elastic ascending and descending aorta and the pulmonary trunk. The ductus arteriosus, a vessel connecting the pulmonary trunk and the aorta during fetal life, constricts shorty after birth and eventually closes. Effective closure occurs only in the case of well developed intimal thickening. Cytokeratin expression during fetal development was greatest in the media of the ascending aorta and pulmonary artery, while in the ductus and descending aorta cytokeratin staining was slight. These results suggest that ductus smooth muscle cells and the smooth muscle cells of the descending aorta show a more advanced differentiation as compared to the ascending aorta and pulmonary artery. At neonatal stages cytokeratin expression in the descending aorta, pulmonary artery and the ascending aorta had disappeared as was expected with increased differentiation. In the neonatal ductus arteriosus reexpression of cytokeratins was found in cell clusters in the hyaluronic acid rich environment of the intimal thickening and in the inner media. Reexpression of cytokeratins, especially when organized in clusters, may reflect changes in gene regulation. Therefore the clusters of cytokeratin positive cells in the ductus may be indicative of extensive changes, occurring during closure of this vessel in the neonatal period, in which inner media and intima are especially involved.
\end{abstract}

J. Slomp · R.E. Poelmann · A.C. Gittenberger-de Groot ( $)$

Department of Anatomy and Embryology,

University of Leiden, P.O. Box 9602,

2300 RC Leiden, The Netherlands

V.E. Koteliansky · M.A. Glukhova

Laboratoire de Physiopathologie du Développement,

CNRS (URA 1337) et Ecole Normale Supérieure,

Paris, France

Ad J.J.C. Bogers

Department of Thoracic Surgery,

Sophia/Dijkzigt University Hospital,

Erasmus University Rotterdam, The Netherlands

\section{Introduction}

Differentiation of vascular smooth muscle cells (SMC) can be characterized by the up and down regulation of several structural proteins. The amount of contractile proteins increases as the SMC become more differentiated [13], whereas the expression of several splice variants of fibronectin [14] and cytokeratins [15] is reported to decrease during development. Cytokeratins are an intermediate filament protein family, normally expressed in epithelial cells and epithelial neoplastic tissues [24]. Expression of the cytokeratins of the simple epithelium type is not restricted to epithelial cells, however, and these cytokeratins are also found in certain cells of mesenchymal origin [36, 37]. For example cytokeratins 8, 18 and 19 have been reported in a number of SMC tumors $[4,16,26,31]$, in vascular SMC during fetal development $[15,36]$ and in pathologic intimal thickening $[15$, 17, 18]. In vascular SMC cytokeratins 8, 18 and 19 are associated with the undifferentiated phenotype during development [15] and the dedifferentiated phenotype in pathologic intimal thickening [18]. In certain SMC it is remarkable that both desmin and vimentin can be co-expressed with the cytokeratins [1], whereas a hyaluronic acid rich environment [19] also seems to be favoured. The latter is a typical phenomenon for the neonatal DA $[8,34]$.

In the present study we have examined the expression of cytokeratins 8,18 and 19 in the human arterial great vessels and focused on the ductus arteriosus (DA) as this vessel has an advanced stage of differentiation of the contractile apparatus during fetal development as compared to the ascending and descending aorta and pulmonary trunk $[20,35]$. The DA is muscular artery connecting the aorta and pulmonary trunk during fetal life. The closure of this vessel shortly after birth is preceded during fetal gestation by the formation of intimal thickening that is essential for effective closure [9]. This physiological intimal thickening resembles the intimal thickening found in arteriosclerosis $[8,34]$. In this way cytokeratin expression can be linked to the various stages of SMC 

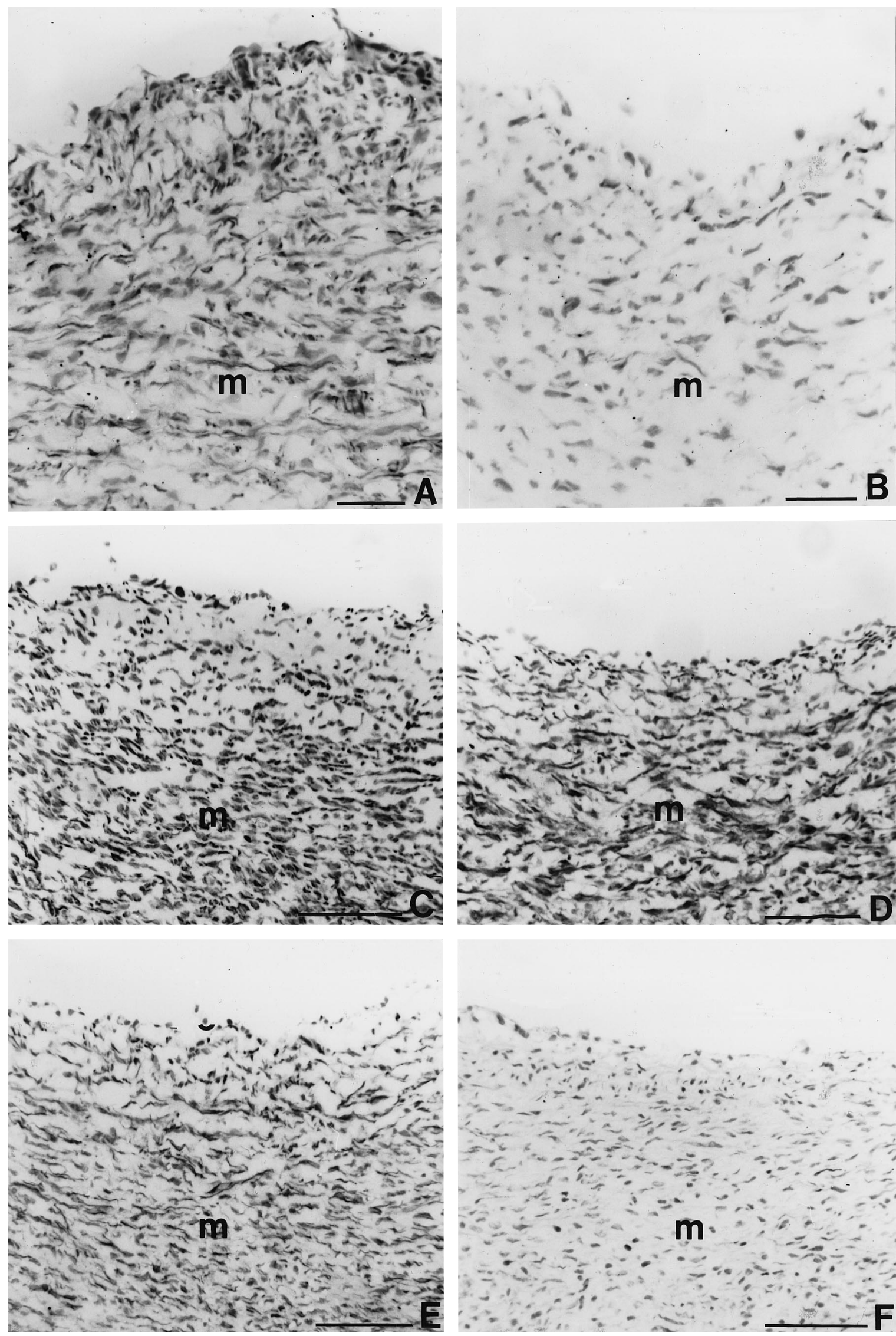
differentiation that are present in the DA and adjoining great vessels during development, including the formation of intimal thickening.

\section{Methods}

Tissue samples

Fetal DA, aorta and pulmonary trunk were obtained from five human fetuses between 13 and 19 weeks of amenorrhea. Two DA did not show signs of intimal thickening (13-15 weeks gestation) and three DA were showing intimal changes (17-19 weeks). The fetuses studied did not show any macroscopically detectable abnormalities. Five normal neonatal DA were resection specimens of the middle part of the DA obtained during cardiac surgery from children between 1 and 3 weeks of age. These children had been treated with prostaglandin $\mathrm{E}_{1}$ to maintain ductal patency. Previous studies have shown that despite the various cardiac malformations the DA of these patients is normal with respect to functional and morphological characteristics $[10,22,34]$. Aortic and pulmonary vessel wall of three similarly treated patients between 1 and 3 weeks of age were used as well as an aorta from a 21-month-old child. Specimens were obtained with approval of the Institutional Review Board of the Dijkzigt University Hospital, the Netherlands. All specimens were rinsed in phosphate buffered saline (PBS) containing 6.8\% sucrose and were submerged in OCT compound (Tissue Tek, Miles Laboratories, Naperville, USA). Specimens were quickly frozen in liquid-nitrogen-chilled isopentane and stored at $20^{\circ} \mathrm{C}$. Sections $(5 \mu \mathrm{m}$ thick $)$ were cut at $-12^{\circ}$ $\mathrm{C}$ and stored at $-20^{\circ} \mathrm{C}$ until immunohistochemistry was performed. To study the morphology of the arteries we used hematoxylin-eosin (HE) and resorcin-fuchsin (RF) staining.

\section{Monoclonal antibodies}

For the detection of cytokeratins 8,18 and 19 several monoclonal antibodies were used. The monoclonal antibodies CAM 5.2 [23] and $M 2 O[32,36]$ are specific for cytokeratin 8. RGE 53 [29] and $R C K 106$ [30] recognized cytokeratin 18 and $R C K 108$ [33] recognized cytokeratin 19.

\section{Immunohistochemistry}

Both the immunofluorescence and the immunoperoxidase method were used. Immediately before use the sections were fixed in cold methanol $\left(-20^{\circ} \mathrm{C}\right)$, followed by a 1-min acetone fixation at room temperature and were air dried for $1 \mathrm{~h}$. The sections were hydrated and rinsed in PBS. For the immunoperoxidase method endogenous peroxidase activity was removed by $15 \mathrm{~min}$ of incubation in PBS containing $0.3 \% \mathrm{H}_{2} \mathrm{O}_{2}$.

The primary antibody was diluted 1:5 in PBS containing $0.1 \%$ bovine serum albumin and $0.05 \%$ Tween- 20 . After an overnight incubation in a moist chamber, three washing steps in PBS were

4 Fig. 1A, B Immunohistochemical staining for cytokeratin 8 of the ascending aorta (A) and ductus arteriosus (B) of a 13-week-old fetus. Staining of the smooth muscle cells of the ascending aorta is stronger than of the smooth muscle cells of the ductus, indicating an advanced differentiation of the smooth muscle cells of the ductus arteriosus. C, D Cytokeratin 8 expression of the ascending aorta $(\mathbf{C})$ and pulmonary artery (D) of a 15-week-old fetus showing an almost similar staining of the smooth muscle cells. E, F In an older fetus (18 weeks) the ascending aorta (E) and pulmonary artery $(\mathbf{F})$ show a difference in that the smooth muscle cells of the pulmonary artery are now almost negative, indicating advanced differentiation of these cells as compared to the smooth muscle cells of the ascending aorta. $m$ media, $\mathbf{A}$ and $\mathbf{B} ;$ bar $50 \mu \mathrm{m}, \mathbf{C}-\mathbf{E}$. In $\mathbf{F}$, bar $100 \mu \mathrm{m}$ performed. For the immunofluorescent detection method we incubated the sections with a TRITC-conjugated rabbit antibody to mouse immunoglobulin (1:50, DAKO A/S, Glostrup, Denmark), washed three times in PBS and mounted in a mixture of $80 \%$ glycerol and 20\% PBS, pH 8.0, containing $1 \mathrm{mg} / \mathrm{ml}$ p-phenylenediamide as anti-fading reagent. For the peroxidase method we used a horseradish peroxidase conjugated rabbit antibody to mouse immunoglobulin (1:300, DAKO A/S) as a secondary antibody. After three washing steps in PBS, the sections were exposed to $0.04 \%$ diaminobenzidine tetrahydrochloride (DAB) in $0.05 \mathrm{M}$ Tris-maleate buffer $(\mathrm{pH} 7.6)$ with $0.006 \% \mathrm{H}_{2} \mathrm{O}_{2}$ for $8 \mathrm{~min}$. The reaction was stopped in PBS and sections were counterstained with hematoxylin. The sections were dehydrated in graded ethanol and mounted in Entellan (Merck, Darmstadt, FRG).

Immunohistochemical staining results were studied by light microscopy and scored by at least two independent researchers.

\section{Results}

\section{Fetal Arteries}

The two fetal DA between 13 and 15 weeks showed no signs of intimal thickening yet. The three fetal DA between 17 and 19 weeks displayed fragmentation of the internal elastic lamina and concomitant lifting of endothelial cells, i.e. the initial signs of intimal thickening formation. In the ascending and descending aorta and the pulmonary trunk no intimal thickening was observed.

The ascending aorta (Fig. 1A, C) and pulmonary trunk (Fig. 1D) of young fetuses between 13 and 15 weeks showed strong expression of cytokeratins 8, 18 and 19. Expression of cytokeratins in the DA (Fig. 1B) and the descending aorta was weak or even absent. In fetuses between 17 and 19 weeks, the expression in the ascending aorta was slightly diminished (Fig. 1E), whereas cytokeratin expression in the pulmonary trunk had decreased (Fig. 1F) to become weaker than the expression in the ascending aorta. Cytokeratin 8 expression in the DA showed a slight increase, while cytokeratin 18 and 19 expression had remained similar to the younger stages. Results are summarized in Table 1.

\section{Neonatal arteries}

The neonatal DA showed well developed intimal thickening. Two of the DA studied had areas of cytolytic necrosis in the media. Cytolytic necrosis is characterized by loss of nuclei without an inflammatory respone [9, 11]. The aorta and pulmonary trunk specimens that were studied showed no signs of intimal thickening.

Neither the neonatal ascending aorta, and pulmonary trunk, nor the ascending aorta and pulmonary trunk from a 21-month-old child, showed any expression of cytokeratin 8 (Fig. 2D), 18 or 19. Results for the descending aorta are described by Glukhova and colleagues [15] and correspond with our data on the ascending aorta and pulmonary artery. The neonatal DA did express cytokeratins 8,18 and 19. There was, however, a variation in expression between the various DA studied. Expression of cytokeratin 8 was the most pronounced, in some DA al- 
Table 1 Results of the immunohistochemical cytokeratin staining reactions in the fetal and neonatal arteries are summarized. The percentage of positive cells was scored from +++ (all cells) to (no cells) using the following catagories: $+++>++>+>+/->+/=>-$.
Except for the neonatal DA (see Results) the interindividual variability of the staining results was low. DA, ductus arteriosus; DAo, descending aorta; AAo, ascending aorta; PT, pulmonary trunk wk, weeks

\begin{tabular}{|c|c|c|c|c|c|c|c|c|c|c|c|c|}
\hline \multirow[t]{2}{*}{ Antigen } & \multicolumn{4}{|c|}{ Fetal (13-15 wk) } & \multicolumn{3}{|c|}{ Fetal (17-19 wk) } & \multicolumn{3}{|c|}{ Neonatal (1-3 wk) } & \multicolumn{2}{|c|}{1.2 year } \\
\hline & DA & DAo & AAo & PT & DA & AAo & PT & DA & AAo & PT & AAo & PT \\
\hline Cytokeratin 8 & $+/=$ & $+/=$ & +++ & +++ & + & ++ & + & $++^{\mathrm{a}}$ & - & - & - & - \\
\hline Cytokeratin 18 & $+/=$ & $+/=$ & ++ & ++ & $+/=$ & + & $+1-$ & $t^{\mathrm{a}}$ & - & - & - & - \\
\hline Cytokeratin 19 & - & - & ++ & ++ & - & + & $+1-$ & $+^{\mathrm{a}}$ & - & - & - & - \\
\hline
\end{tabular}

a Staining localized in cell clusters

Fig. 2A-D Neonatal ductus arteriosus stained for cytokeratin 8. A Expression of cytokeratin 8 was found in the intima $(i)$ and inner media (im), the outer media being negative. B Higher magnification of a positive area, in which cytokeratin expression was found in almost every cell. C Cluster of cytokeratin positive cells (arrows) in the intima in another neonatal ductus (C). D The media $(m)$ of the neonatal ascending aorta was negative for cytokeratin 8; bar $100 \mu \mathrm{m}$
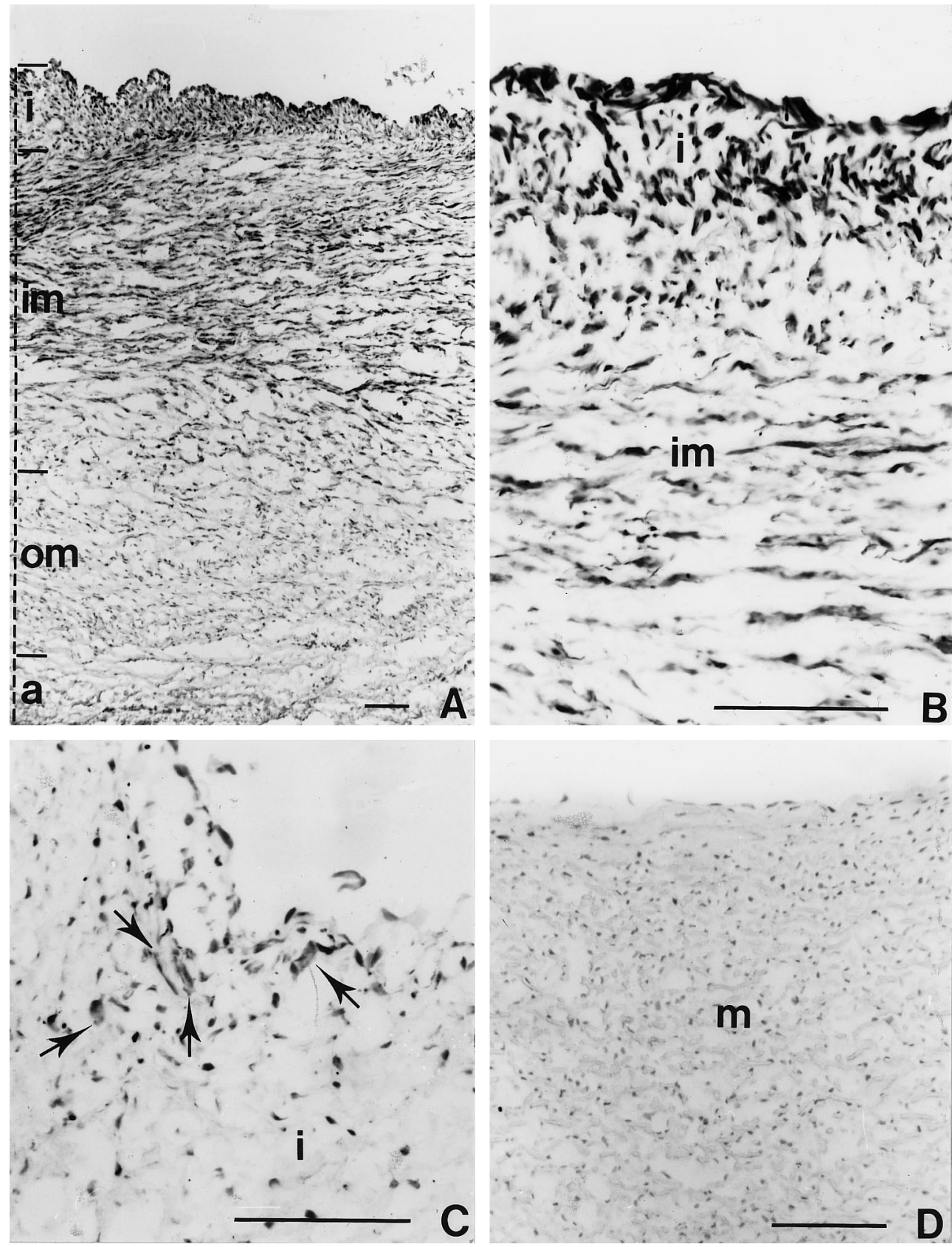

m 

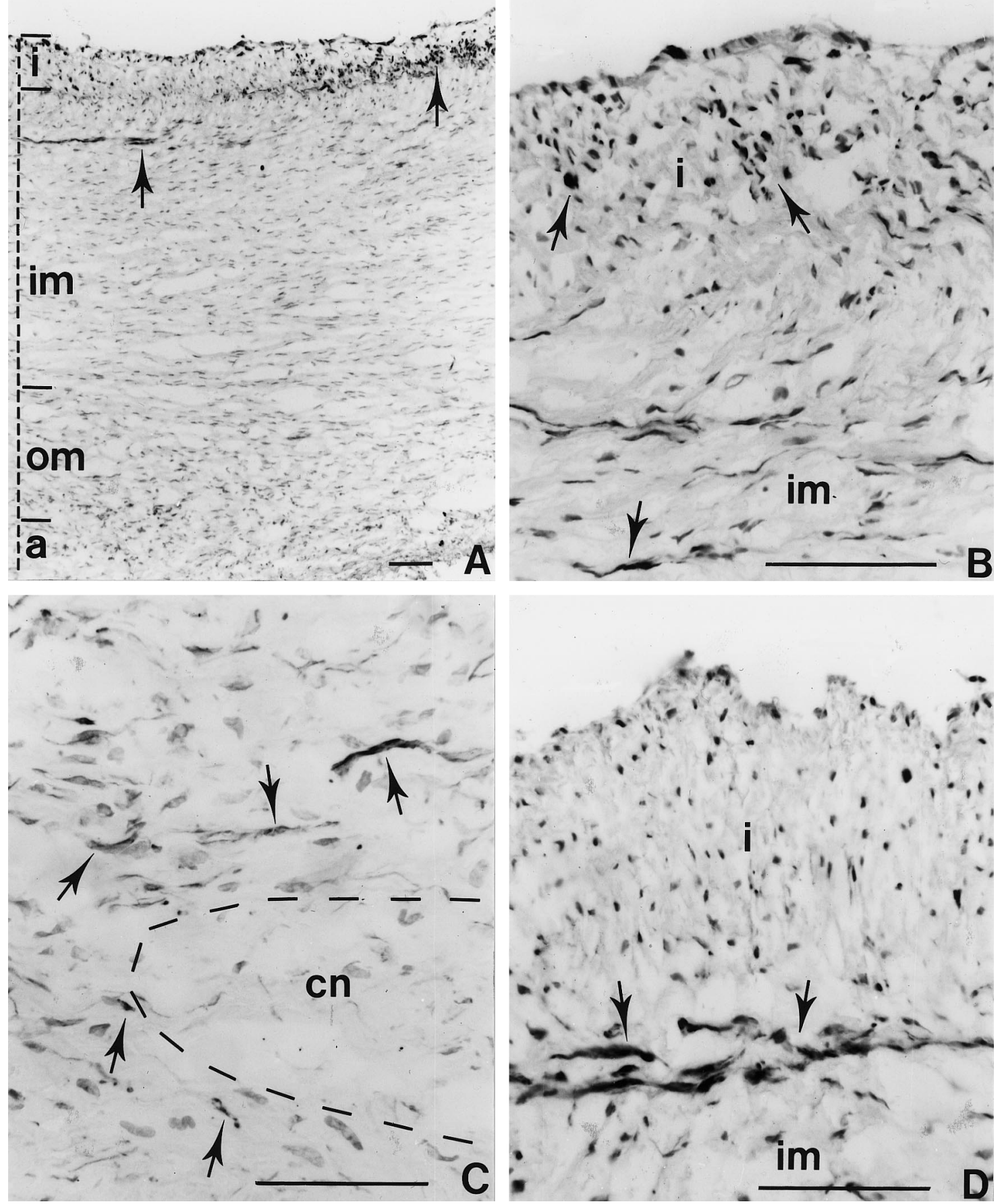

Fig. 3 A Cytokeratin 18 expression was found in cell clusters (arrows) present in all parts of the vessel wall of the ductus arteriosus except in the outer media. B, C Detail of cytokeratin-positive cell clusters (arrows) in the intima (i) and inner media (im) (B) and surrounding the areas with cytolytic necrosis $(c n)(\mathbf{C})$. D Detail of a cytokeratin-19-positive cluster on the border of the intima and inner media ( (m); bar, $100 \mu \mathrm{m}$

cytokeratin-positive cells were found around areas of cytolytic necrosis (Fig. 3C) and in areas showing onset of cytolytic necrosis, but we also encountered randomly localized clusters of positive cells. No clusters were found in the outer media. The results are summarized in Table 1.

most every SMC was stained except in the outer media (Fig. 2A, B). Other DA showed clusters of cytokeratin-8positive cells located in the intima (Fig. 2C) and inner media. Expression of cytokeratin 18 (Fig. 3A-C) and 19 (Fig. 3D) was also found in cell clusters. Clusters of

\section{Discussion}

In this study we have examined the expression of cytokeratins 8, 18 and 19 in SMC of the arterial great vessels 
during development. In the adult cytokeratins are generally known as markers of epithelial differentiation and belong to the family of intermediate filaments [24]. These intermediate filaments consist of six subtypes, classifying different tissue types. Type I are the small acidic cytokeratins (9-20) and type II are the large neutral to basic cytokeratins (1-8). The third class, type III of the intermediate filaments, is formed by the mesenchymal protein vimentin, the muscle protein desmin, the glial fibrillary acidic protein expressed in glial cells and astrocytes, and peripherin, specific for neuronal cells. Neurofilaments are type IV, nuclear laminins A and B type $\mathrm{V}$, and nestin, an intermediate filament specific to central nervous system stem cells, is type VI. In pathological situations and in tumors, these cell lineage markers are generally retained, although switches in expression have been described [24]. Coexpression of two or three intermediate filaments in one single cell has been reported. SMC coexpress vimentin, desmin and cytokeratins under certain conditions, such as during fetal development [36] and SMC oncogenesis [16]. Furthermore, the cytokeratins can be used as markers of SMC differentiation, as expression of cytokeratins in vascular SMC is observed during early fetal development, whereas normal adult SMC do not express cytokeratins [15]. In a 10-week-old embryo SMC of the descending aorta contained cytokeratin 8 [15]. In the present study we found that cytokeratin expression in fetuses between 13 and 15 weeks was very low in the descending aorta and DA. In contrast the ascending aorta and pulmonary trunk show a high expression, suggesting that SMC of the DA and descending aorta are already more differentiated than those of the pulmonary trunk and the ascending aorta. The special status of the ascending aorta and pulmonary trunk with regard to SMC differentiation has also been described on the basis of actin expression [3, 12]. In the avian and mouse embryo this region shows transient loss of actin expression. We do not know whether differences in embryonic origin, mesenchymal versus neural crest, are related to these phenomena $[3,12,25]$. Differences in differentiation between the SMC of the ascending and descending aorta were encountered in this study with the cytokeratins, and in a previous study [35] with EDA and EDB splice variants of fibronectin, all markers of early SMC differentiation. Since the SMC of the ascending and descending aorta show various differences in phenotype, varying results can be expected in studies using aortic tissue from different origins. A difference in differentiation between SMC of the ascending and descending aorta was not encountered in studies [20, 35] using SMC contractile proteins, being markers of late SMC differentiation. These studies showed that the SMC of both the ascending and descending aorta were less differentiated than SMC of the DA. The early appearance of the contactile proteins in the DA may be related to the intense effective contraction of the SMC when the DA closes shortly after birth. We could also show, as reported $[1,16,36]$ that the SMC of the DA express desmin, vimentin [35] and cytokeratin. It is re- marked in this respect that the DA has a large amount of hyaluronic acid in both the intima and inner media [8, $30]$, a correlation that was reported by Kasper and colleagues [19].

Cytokeratin re-expression in the DA was observed in clusters of positive cells at neonatal stages. There was also an overall variation in cytokeratin expression between the neonatal DA studied. This variation may have been due to different stages of maturation and closure of the DA in the neonate [9]. Our study shows that the clusters of cytokeratin positive cells did not colocalize with the dedifferentiated areas defined by the absence of cytoskeletal and contractile protein differentiation markers and the presence of EDA: Extra Domain A and EDB: Extra Domain B fibronectin. These were found in the inner intima and areas of cytolytic necrosis containing apoptotic cells [35]. These apoptotic areas are widely extended during the anatomical closure of the ductus, but were not observed in the outer media (unpublished results). We have no explanation for the special behaviour of SMC in the outer media, as this area in the DA is cytokeratin-negative, thus resembling the adjoining elastic vessels. Recent published data [7] show that the outer media has specific SMC differentiation indicated by the expression of a retinoic acid responsive SMC phenotype. The intima and inner media of the DA are actively involved in the process of intimal thickening in the DA [34] and undergo extensive changes during closure of the DA $[9,35]$. The outer media does not take part in these processes. Restriction of the location of cytokeratin positive cells in the neonatal DA may therefore be related to these phenomena. A direct link with proliferation of SMC could not be made (unpublished results). Reexpression of cytokeratins has also been described in pathologic intimal thickening $[15,17,18]$. In fibromuscular lesions, particularly those found in vein grafts, cytokeratin-positive cells are also found in clusters [18]. The presence of clusters might relate to a number of phenomena. It is possible that cells in the vessel wall produce a diffusible factor that is involved in the induction of cytokeratin expression [18]. It may also be that these cells are monoclonal, as was found for large proportions of the atherosclerotic plaques [2]. Another explanation for the presence of clusters of cytokeratin-positive cells may be that these cells are intrinsically unstable in their expression of genes encoding cytokeratins 8 and 18, as has been observed for clusters of cytokeratin-positive cells in transformed non-epithelial cells [21]. Finally, reexpression of cytokeratins may reflect rearrangement of the regulation of gene expression [15], as the expression of cytokeratin 8 and 18 is dependent on the extent of DNA methylation [27] and requires the coexpression of c-jun and c-fos proto-oncogene transcription factors [28].

The latter explanation may be the most suitable for the situation in the neonatal ductus, as this vessel is undergoing many changes particularly in the intima and inner media where the cytokeratin clusters are found during postnatal closure $[5,6]$. 


\section{References}

1. Bader BL, Jahn L, Franke WW (1988) Low level expression of cytokeratins 8,18 and 19 in vascular smooth muscle cells of the human umbilical cord and in cultured cells derived therefrom, with an an analysis of the chromosomal locus containing the cytokeratin 19 gene. Eur J Cell Biol 47:300-319

2. Benditt EP, Benditt JM (1973) Evidence for a monoclonal origin of human atherosclerotic plaques. Proc Natl Acad Sci USA 70:1753-1756

3. Bergwerff M, DeRuiter MC, Poelmann RE, Gittenberger-de Groot AC (1996) Onset of elastogenesis and downregulation of smooth muscle actin as distinguishing phenomena in artery differentiation in the chick embryo. Anat Embryol 194:545-557

4. Brown DC, Theaker JM, Banks PM, Gatter KC, Mason DY (1987) Cytokeratin expression in smooth muscle and smooth muscle tumours. Histopathology 11:477-486

5. Clyman RI (1987) Ductus arteriosus: current theories of prenatal and postnatal regulation. Sem Perinatol 11:64-71

6. Coceani F, Kelsey L, Ackerley C, Rabinovitch M (1994) Cytochrome P450 during ontogenic development: occurrence in the ductus arteriosus and other tissues. Can J Physiol Pharmacol 72:217-226

7. Colbert MC, Kirby ML, Robbins J (1996) Endogenous retinoic acid signalling colocalizes with advanced expression of the adult smooth muscle myosin heavy chain isoform during development of the ductus arteriosus. Circ Res 78:790-798

8. DeReeder EG, Girard N, Poelmann RE, van Munsteren JC Patterson DF, Gittenberger-de Groot AC (1988) Hyaluronic acid accumulation and endothelial cell detachment in intimal thickening of the vessel wall. The normal and genetic defective ductus arteriosus. Am J Pathol 132:574-585

9. Gittenberger-de Groot AC, van Ertbruggen I, Moulaert AJM, Harinck E (1980) The ductus arteriosus in the preterm infant: histologic and clinical observations. J Pediat 96:88-93

10. Gittenberger-de Groot AC, Sutherland K, Sauer U, Kellner M, Schöber JG, Bühlmeyer K (1980) Normal and persistent ductus arteriosus influenced by prostaglandin $\mathrm{E}_{1}$. Hist Clin Obs 5:361-368

11. Gittenberger-de Groot AC, Strengers J (1988) Histopathology of the arterial duct (ductus arteriosus) with an without treatment with prostaglandin $\mathrm{E}_{1}$. Int J Cardiol 19:153-166

12. Gittenberger-de Groot AC, Slomp J, DeRuiter MC, Poelmann RE (1995) Smooth muscle cell differentiation during early development and during intimal thickening formation in the ductus arteriosus.In: Schwartz SM, Mecham R (eds) The vascular smooth muscle cell. Academic Press, New York, pp 17-36

13. Glukhova M, Frid M, Koteliansky V (1990) Developmental changes in expression of contractile and cytoskeletal proteins in human aortic smooth muscle. J Biol Chem 265:1304213046

14. Glukhova M, Frid M, Shekhonin B, Balabanov YV, Koteliansky V (1990) Expression of fibronectin variants in vascular and visceral smooth muscle in development. Dev Biol 141:193-202

15. Glukhova MA, Shekhonin BV, Kruth H, Kotelianksy VE (1991) Expression of cytokeratin 8 in human aortic smooth muscle cells. Am J Physiol 261 (Suppl):72-77

16. Gown AM, Boyd HC, Chang Y, Ferguson M, Reichler B, Tippens D (1988) Smooth muscle cells can express cytokeratins of "simple" epithelium: Immunocytochemical and biochemical studies in vitro and in vivo. Am J Path 132:223-232

17. Jahn L, Franke WW (1989) High frequency of cytokeratinproducing smooth muscle cells in human atherosclerotic plaques. Differentiation 40:55-62

18. Jahn L, Kreuzer J, von Hodenberg E, Kübler W, Franke WW, Allenberg J, Izumo S (1993) Cytokeratins 8 and 18 in smooth muscle cells. Detection in human coronary artery, peripheral vascular, and vein graft disease and in transplantation-associated arteriosclerosis. Arterioscler Thromb 13:1631-1639

19. Kasper M, Stosiek P, Karsten U (1988) Coexpression of cytokeratins and vimentin in hyaluronic acid-rich tissues. Acta Histochem 84:107-108
20. Kim H-S, Aikawa M, Kimura K, Kuro-o M, Nakahara K, Suzuki T, Katoh H, Okamoto E, Yazaki Y, Nagai R (1993) Ductus arteriosus. Advanced differentiation of smooth muscle cells demonstrated by myosin heavy chain isoform expression in rabbits. Circulation 88:1804-1810

21. Knapp AC, Franke WW (1989) Spontaneous losses of control of cytokeratin gene expression in transformed, non-epithelial human cells occurring at different levels of regulation. Cell 59:67-79

22. Korula A, Calder AL, Neutze JM (1991) Effects of prostaglandin $\mathrm{E}_{1}$ given in low doses on the histopathology of the arterial duct. In J Cardiol 33:215-222

23. Makin CA, Bobrow LG, Bodmer WF (1984) A monoclonal antibody to cytokeratin for use in routine histopathology. J Clin Pathol 37:975-983

24. Nagle RB (1994) A review of intermediate filament biology and their use in pathologic diagnosis. Mol Biol Rep 19:3-21

25. Noden DM, Poelmann RE, Gittenberger-de Groot AC (1995) Cell origins and tissue boundaries during outflow tract development. Trends Cardiovasc Med 5:69-75

26. Norton AJ, Thomas JA, Isaacson PG (1987) Cytokeratin-specific monoclonal antibodies are reactive with tumous of smooth muscle derivation. An immunohistochemical and biochemical study using antibodies to intermediate filament cytoskeletal proteins. Histopathology 11:487-499

27. Oshima RG, Trevor K, Shevinsky LH, Ryder OA, Ceceña G (1988) Identification of the gene for coding for the endo B murine cytokeratin and its methylated stable inactive state in mouse nonepithelial cells. Genes Dev 2:505-516

28. Oshima RG, Abrams L, Kulesh D (1990) Activation of an intron enhancer within the keratin 18 gene by expression of cfos and c-jun in undifferentiated F9 embryonal carcinoma cells. Genes Dev 4:835-848

29. Ramaekers F, Huysmans A, Moesker O, Kant A, Jap P, Herman C, Vooijs P (1983) Monoclonal antibody to keratin filaments, specific for glandular epithelia and their tumors: use in surgical pathology. Lab Invest 49:353-361

30. Ramaekers F, Huysmans A, Schaart G, Moesker O, Vooijs P (1987) Tissue distribution of keratin 7 as monitored by a monoclonal antibody. Exp Cell Res 170:235-249

31. Ramaekers FCS, Pruszczynski M, Smedts F (1988) Cytokeratins in smooth muscle cells and smooth muscle tumours. Histopathology 12:558-561

32. Schaafsma HE, Ramaekers FCS, Van Muyen GNP, Ooms ECM, Ruiter DJ (1989) Distribution of cytokeratin polypeptides in epithelia of the adult urinary tract. Histochemistry 91:151-159

33. Smedts F, Ramaekers F, Link M, Lauerovà L, Troyanovsky S, Schijf C, Vooijs P (1994) Detection of keratin subtypes in routinely processed cervical tissue: implications for tumor classification and the study of cervix cancer etiology. Virchows Arch 425:145-155

34. Slomp J, van Munsteren JC, Poelmann RE, DeReeder EG, Bogers AJJC, Gittenberger-de Groot AC (1992) Formation of intimal cushions in the ductus arteriosus as a model for vascular intimal thickening. An immunohistochemical study of changes in extracellular matrix components. Atherosclerosis 93:25-39

35. Slomp J, Gittenberger-de Groot AC, Glukhova MA, van Munsteren JC, Kockx MM, Schwartz SM, Koteliansky VE (1997) Differentiation, dedifferentiation and apoptosis of smooth muscle cells during the development of the human ductus arteriosus. Arterioscler Thromb Vasc Biol (in press)

36. Van Muijen GNP, Ruiter DJ, Warnaar SO (1987) Coexpression of intermediate filament polypeptides in human fetal and adult tissues. Lab Invest 57:359-369

37. Viragh S, Gittenberger-de Groot AC, Poelmann RE, Kalman F (1993) Early development of quail heart epicardium and associated vascular and glandular structures. Anat Embryol 188:381-393 